\title{
LOS ENFOQUES ACOTADOS DEL CONTROL DE CONVENCIONALIDAD: LAS ÚNICAS VERSIONES ACEPTABLES DE ESTA DOCTRINA
}

\author{
THE DELIMITED UNDERSTANDINGS OF CONVENTIONALITY \\ CONTROL:
} THE ONLY ACCEPTABLE VERSIONS OF THIS DOCTRINE*

ÁLVARO PAÚL DÍAZ**

\section{RESUMEN}

El control de convencionalidad $(\mathrm{CCv})$ busca que los Estados se abstengan de aplicar normas contrarias a la Convención Americana sobre Derechos Humanos (CADH) o a la jurisprudencia de la Corte Interamericana de Derechos Humanos. Dicha doctrina podría requerir que los jueces y otros órganos nacionales dejen sin aplicación la legislación nacional que sea contraria a la CADH o a la interpretación que de ella haga la Corte Interamericana. El CCv puede interpretarse de dos modos: 1) afirmando que los órganos nacionales deben aplicarlo, aún cuando éstos no cuenten con la competencia para hacerlo, y 2) diciendo que los órganos nacionales

\footnotetext{
* Este trabajo corresponde una versión traducida, corregida y actualizada de aquella publicada en inglés en la Revue Générale de Droit, Special Issue, 2019, N 49, contando con la autorización para su publicación en español.

Agradezco la ayuda de Camilo Ibáñez Escobar y los comentarios de Pablo González Domínguez.

** Profesor de Derecho Internacional y de Derechos Humanos, Pontificia Universidad Católica de Chile. Licenciado en Ciencias Jurídicas por la Universidad de los Andes (Chile), Máster en Derecho (MJur) por la Universidad de Oxford y Doctor en Derecho (PhD) del Trinity College Dublin. El autor ha sido pasante en la Corte y la Comisión Interamericanas y visitante en el Tribunal Europeo de Derechos Humanos. Correo electrónico: alvaro.paul@uc.cl.

Artículo recibido el 26 de noviembre de 2018, y aceptado para su publicación el 14 de noviembre de 2019.
} 
debieran aplicar el $\mathrm{CCv}$ en la medida de sus competencias, de acuerdo con su Constitución nacional. Solo esta última interpretación es compatible con los principios del Derecho internacional y podría ser aceptada por todos los Estados miembros. Este trabajo expone dicha interpretación y sus beneficios frente a la interpretación extensiva del control de convencionalidad.

Palabras clave: Bloque de Constitucionalidad, Corte Interamericana de Derechos Humanos, Control de Convencionalidad, Competencia, Interpretación, Tratado auto-ejecutable.

\section{ABSTRACT}

The doctrine of conventionality control $(\mathrm{CvC})$ intends to prevent States from applying norms that run counter to the American Convention on Human Rights (ACHR) or to the Inter-American Court's case law. This doctrine may require judges and other domestic bodies to abstain from applying domestic norms that are incompatible with the ACHR or with the Inter-American Court's interpretation of it. $\mathrm{CvC}$ may be interpreted in two ways: 1) stating that domestic bodies should apply it, even if they have no constitutional power to do so, and 2) affirming that domestic bodies should apply it to the extent of their powers, according to their national constitutions. Only the latter interpretation is compatible with the principles of international law, and may be accepted by all member States. This paper presents this interpretation and its benefits over the extensive understanding of conventionality control.

Keywords: Constitutional Block, Inter-American Court of Human Rights, Conventionality Control, Interpretation, Jurisdiction, Self-executing treaty.

\section{INTRODUCCIÓN}

La Corte Interamericana de Derechos Humanos tiene un rol principal en el sistema interamericano de protección de los derechos humanos. Consciente de su papel, la Corte busca tener un amplio impacto en el panorama de los derechos humanos en el Hemisferio, para lo cual desarrolló la doctrina del control de convencionalidad, que busca expandir el efecto de sus sentencias. Los académicos han escrito mucho sobre el control de 
convencionalidad, sus orígenes y sus implicancias. ${ }^{1}$ En términos generales, esta doctrina es algo similar a la idea de control de constitucionalidad, pero con varias diferencias clave, principalmente, su aplicación en el ámbito del Derecho internacional. Esta doctrina es bastante nueva, por lo que sus contornos no son totalmente claros, y los autores y los poderes judiciales nacionales tienen diferentes interpretaciones de la misma.

Según ciertas interpretaciones, mediante la doctrina del control de convencionalidad, la Corte Interamericana afirmaría tener poderes supranacionales, superiores a los de cualquier otro tribunal internacional o regional (incluso más altos que los del Tribunal de Justicia de la Unión Europea, y comparable solo a los de los tribunales constitucionales nacionales ${ }^{2}$ ). Dichas interpretaciones parecen coincidir con lo que afirma la Corte en sus fallos (como discutiremos al tratar del enfoque extensivo del control de convencionalidad), pero tienen serias consecuencias. Por otro lado, hay algunos autores y jueces que, haciendo uso de algunas declaraciones de la Corte, están interpretando la doctrina del control de convencionalidad de una manera más acotada. Si se aceptara esta interpretación, la doctrina del control de convencionalidad superaría sus propias complejidades, para ser reconocida más globalmente como una doctrina legítima y respetuosa del Derecho internacional que podría ser ampliamente apoyada.

\section{DESCRIPCIÓN GENERAL DE LA DOCTRINA DEL CONTROL DE CONVENCIONALIDAD}

\subsection{Descripción general de la doctrina}

La Corte Interamericana articuló por primera vez la doctrina del control de convencionalidad en su caso de 2006, Almonacid Arellano v. Chile, ${ }^{3}$ aunque el juez García Ramírez ya había sentado sus bases unos años

1 Para una explicación detallada de esta doctrina, véase Dulitzky, Ariel E., "An Inter-American Constitutional Court? The Invention of the Conventionality Control by the Inter-American Court of Human Rights", Texas International Law Journal, 2015, N 50, p. 45.

2 Ibid., pp. 60-62.

3 Corte Interamericana de Derechos Humanos (en adelante Corte IDH), 26 de septiembre de 2006, Almonacid Arellano et al. v. Chile, Excepciones Preliminares, Fondo, Reparaciones y Costas (ser. C) No 154, párrs. 123-125. Algunos autores ven los orígenes de esta doctrina en otras sentencias. FERRER MACGrEGOR, Eduardo, "El Control de Convencionalidad en la Jurisprudencia de la Corte Interamericana de Derechos Humanos (A Una Década de su Creación: 2006-2016)", en: Henríquez, M.; Morales, M. 
antes, en una serie de votos separados. ${ }^{4}$ Previo a eso, el Tribunal tenía un enfoque muy diferente respecto al efecto directo de la CADH. ${ }^{5}$

Debido a la creación relativamente reciente de esta doctrina por parte de la Corte, existen "importantes aspectos no resueltos y controvertidos acerca sus fundamentos normativos y efectos jurídicos". ${ }^{6}$ En sus más de diez años de existencia ante la Corte, el contenido del control de convencionalidad ha cambiado de manera sustantiva. Se ha afirmado que estos cambios son una muestra de incoherencia, ${ }^{7}$ pero también que son simple expresión de un proceso gradual de creación y definición de una doctrina por parte de un tribunal. ${ }^{8}$ Antes de describir esta doctrina con mayor detalle, es importante aclarar que no existe duda de que la CADH es vinculante para los Estados Partes, al igual que las sentencias dictadas por la Corte Interamericana dentro de sus competencias, en relación con el Estado demandado. ${ }^{9}$

Aunque haya diferentes lecturas del alcance de la doctrina del control de convencionalidad, es posible decir que -según las sentencias de la propia Corte- esta doctrina exige que los jueces nacionales, y cualquier otro órgano que aplique la ley dentro de un Estado parte en la $\mathrm{CADH}$, evalúen ex officio si las leyes internas son compatibles con la CADH y con la interpretación que de ella haga la Corte Interamericana; si son incompatibles, la doctrina del

(eds.), El Control de Convencionalidad: Un Balance Comparado a 10 Años de Almonacid Arellano vs. Chile, Ediciones Der, Santiago, 2017, pp. 38-40.

${ }^{4}$ Por ejemplo, Corte IDH, 7 de septiembre de 2004, Tibi v. Ecuador, Excepciones Preliminares, Fondo, Reparaciones y Costas, Sentencia (ser. C) No 114, voto concurrente del juez García Ramírez párr. 3; y Corte IDH, 1 de febrero de 2006, López Álvarez v. Honduras, Fondo, Reparaciones y Costas (ser. C) $N^{\circ} 141$, voto concurrente del juez García Ramírez, párr. 30.

${ }^{5} \mathrm{La}$ Corte consideraba que no podía pronunciarse sobre el efecto de la CADH en el Derecho interno de los Estados. Fuentes TorriJo, Ximena, "International and Domestic Law: Definitely an Odd Couple", Revista Jurídica de la Universidad de Puerto Rico, 2008, N 77, pp. 485-487.

6 Carozza, Paolo G.; GonzÁlez, Pablo, "The Final Word? Constitutional Dialogue and the InterAmerican Court of Human Rights: A Reply to Jorge Contesse", International Journal of Constitutional Law, 2017, Vol. 15, $\mathrm{N}^{\circ}$ 2, p. 347 (traducido por el autor). Ver Castilla JuÁRez, Karlos A., “¿Control Interno o Difuso de Convencionalidad? Una Mejor Idea: La Garantía de Tratados", Anuario Mexicano de Derecho International, 2013, $\mathrm{N}^{\circ}$ XIII.

7 Castilla, cit. (n. 6), pp. 56-68.

${ }^{8}$ Por ejemplo, García Ramírez, Sergio, "Control de Convencionalidad” en: Henríquez, M.; Morales, M. (eds.), El Control de Convencionalidad: Un Balance Comparado a 10 Años de Almonacid Arellano vs. Chile, Ediciones Der, Santiago, 2017, pp. 22-23, y Julio Estrada, Alexei, "Comentario al Artículo 'Control de Convencionalidad Interamericano: Una Mera Aplicación del Derecho Internacional', de Karlos A. Castilla Juarez”, Revista Derecho del Estado (U. Externado de Colombia), 2015, № 34, pp. 52-53.

${ }^{9}$ La única excepción a esto sería una violación del principio extra compromissum arbiter nihil facere potest. 
control de convencionalidad requeriría que los jueces -y los otros órganos que aplican la ley-, rechacen o se abstengan de hacer cumplir sus leyes nacionales (aunque la Opinión Consultiva $\mathrm{N}^{\circ} 24$ parece haber moderado algo esta última exigencia). ${ }^{10}$ Esta obligación existiría también cuando la interpretación de la Corte Interamericana de Derechos Humanos se hubiera emitido en una sentencia relativa a un Estado diferente, ${ }^{11}$ e incluso si esta interpretación contradice las constituciones políticas nacionales. ${ }^{12}$

Al realizar este control de convencionalidad, los agentes o funcionarios nacionales deben "tener en cuenta no solamente el tratado, sino también la interpretación que del mismo ha hecho la Corte Interamericana", ${ }^{13}$ porque la Corte se considera a sí misma "intérprete última de la Convención Americana". ${ }^{14}$ En Gelman v. Uruguay la Corte afirmó que los jueces tenían la misión de hacer que la CADH prevalezca sobre las normas, interpretaciones y prácticas internas que pueden obstaculizar el cumplimiento de las sentencias de la Corte. ${ }^{15}$

${ }^{10}$ La regla sobre rechazar o dejar sin aplicación la ley se puede observar en Corte IDH, 20 de marzo de 2013, Gelman v. Uruguay, Supervisión de Cumplimiento de Sentencia, Resolución de la Corte, párr. 69. Lo afirmado respecto de la Opinión Consultiva $N^{\circ} 24$ se aprecia en que dicha opinión no exige dejar sin efecto la normativa nacional que requiere la diferencia de sexo para contraer matrimonio. En efecto, señala que algunos Estados deben "vencer dificultades institucionales para adecuar su legislación interna", por lo que solo "insta" a los Estados "a que impulsen realmente y de buena fe las reformas legislativas, administrativas y judiciales necesarias para adecuar sus ordenamientos, interpretaciones y prácticas internos" a los requerimientos de dicha opinión. Corte IDH, 24 de noviembre de 2017, Identidad de Género, e Igualdad y No Discriminación a Parejas del Mismo Sexo. Obligaciones Estatales en Relación con el Cambio de Nombre, la Identidad de Género, y los Derechos Derivados de un Vinculo entre Parejas del Mismo Sexo (Interpretación y Alcance de los Artículos 1.1, 3, 7, 11.2, 13, 17, 18 y 24, en Relación con el Artículo 1 de la Convención Americana sobre Derechos Humanos), Opinión Consultiva OC-24/17 (ser. A) ํ2 24, párr. 226.

${ }^{11}$ Corte IDH, 26 de septiembre de 2006, Almonacid Arellano et al. v. Chile, Excepciones Preliminares, Fondo, Reparaciones y Costas (ser. C) No 154, párrs. 124 \& 127.

${ }^{12}$ Corte IDH, 20 de noviembre de 2007, Boyce y otros v. Barbados, Excepción Preliminar, Fondo, Reparaciones y Costas, Sentencia (ser. C) N 169, párrs. 75-80.

${ }^{13}$ Corte IDH, 26 de noviembre de 2010, Cabrera García y Montiel Flores v. México, Excepciones Preliminares, Fondo, Reparaciones y Costas, Sentencia (ser. C) N 220, párr. 225.

${ }^{14}$ Corte IDH, 26 de noviembre de 2010, Cabrera García y Montiel Flores v. México, Excepciones Preliminares, Fondo, Reparaciones y Costas, Sentencia (ser. C) № 220, párr. 225.

${ }^{15}$ Corte IDH, 20 de marzo de 2013, Gelman v. Uruguay, Supervisión de Cumplimiento de Sentencia, Resolución de la Corte, párr. considerando 73. Esto se ha interpretado como diciendo que las autoridades nacionales tienen un deber mayor de ejercer el control de convencionalidad cuando la Corte ha declarado explícitamente la inconvencionalidad de una norma en particular (GonzÁlez Domínguez, Pablo, "La Doctrina del Control de Convencionalidad a la Luz del Principio de Subsidiariedad", Estudios Constitucionales, 2017, Vol. 15, № 1, p. 72). Sin embargo, es discutible que sea posible hablar de un deber mayor o menor en el Derecho internacional. El autor citado parece considerar que siempre que el deber es mayor, el Estado debe seguir estrictamente el estándar establecido en la sentencia, mientras 
Según las propias palabras de la Corte, habría dos manifestaciones del control de convencionalidad, dependiendo de si la sentencia se dictó en un caso en el cual el Estado fue o no parte. Así, según la Corte,

"cuando existe una sentencia internacional dictada con carácter de cosa juzgada respecto de un Estado que ha sido parte en el caso sometido a la jurisdicción de la Corte Interamericana, todos sus órganos, incluidos sus jueces y órganos vinculados a la administración de justicia, también están sometidos al tratado y a la sentencia de este Tribunal, lo cual les obliga a velar para que los efectos de las disposiciones de la Convención $\mathrm{y}$, consecuentemente, las decisiones de la Corte Interamericana, no se vean mermados por la aplicación de normas contrarias a su objeto y fin o por decisiones judiciales o administrativas que hagan ilusorio el cumplimiento total o parcial de la sentencia. Es decir, en este supuesto, se está en presencia de cosa juzgada internacional, en razón de lo cual el Estado está obligado a cumplir y aplicar la sentencia". ${ }^{16}$

En cambio — continúa la Corte_-, cuando el Estado

"no ha sido parte en el proceso internacional en que fue establecida determinada jurisprudencia, por el solo hecho de ser Parte en la Convención Americana, todas sus autoridades públicas y todos sus órganos, incluidas las instancias democráticas, jueces y demás órganos vinculados a la administración de justicia en todos los niveles, están obligados por el tratado, por lo cual deben ejercer, en el marco de sus respectivas competencias y de las regulaciones procesales correspondientes, un control de convencionalidad tanto en la emisión y aplicación de normas, en cuanto a su validez y compatibilidad con la Convención, como en la determinación, juzgamiento y resolución de situaciones particulares y casos concretos, teniendo en cuenta el propio tratado y, según corresponda, los precedentes o lineamientos jurisprudenciales de la Corte Interamericana". ${ }^{17}$

que un Estado con un deber menor puede encontrar diferentes maneras de aplicar el estándar de la Corte (Ibid., pp. 88-90).

${ }^{16}$ Corte IDH, 20 de marzo de 2013, Gelman v. Uruguay, Supervisión de Cumplimiento de Sentencia, Resolución de la Corte, párr. considerando 68.

${ }^{17}$ Ídem, párr. considerando 69. 
Los autores de la CADH no tuvieron la intención de establecer el control de convencionalidad. El único momento en el que se mencionó explícitamente una idea similar dentro del sistema interamericano fue durante la discusión de la Declaración Americana de los Derechos y Deberes del Hombre (no de la CADH). ${ }^{18}$ Sin embargo, los autores de la Declaración Americana abandonaron esta idea cuando acordaron que la Declaración no tendría ningún efecto vinculante. ${ }^{19}$ Por el contrario, los redactores de la CADH no discutieron nada similar, aunque algunos representantes consideraron que ciertas normas de la CADH eran directamente aplicables. ${ }^{20}$ Sin embargo, la Corte Interamericana de Derechos Humanos sostiene que es posible extraer la doctrina del control de convencionalidad de algunas disposiciones del tratado. La doctrina sería "el resultado de una interpretación progresiva e innovadora de los artículos 1.1 y 2 de la CADH, y de los artículos 26 y 27 de la Convención de Viena sobre el Derecho de los Tratados (CVDT)". ${ }^{21}$ Ferrer Mac-Gregor argumenta que también los artículos 29 y 25 de la $\mathrm{CADH}$ desempeñan un papel en la creación del control de convencionalidad. ${ }^{22}$

El artículo 2 de la CADH es el que más se alega para fundamentar el control de convencionalidad. Este artículo establece:

Si el ejercicio de los derechos y libertades mencionados en el artículo 1 no estuviere ya garantizado por disposiciones legislativas o de otro carácter, los Estados Partes se comprometen a adoptar, con arreglo a sus procedimientos constitucionales y a las disposiciones de esta Convención, las medidas legislativas o de otro carácter que fueren necesarias para hacer efectivos tales derechos y libertades. ${ }^{23}$

Se ha afirmado que el control de convencionalidad podría considerarse

\footnotetext{
${ }^{18}$ Paúl, Álvaro, Los Trabajos Preparatorios de la Declaración Americana de los Derechos y Deberes del Hombre y el Origen Remoto de la Corte Interamericana, Universidad Nacional Autónoma de México, Instituto de Investigaciones Jurídicas, México, 2017, pp. 50-53.

${ }^{19}$ Ibid.

${ }^{20}$ Ver, por ejemplo, Secretaría General de la Organización de los Estados Americanos, Conferencia Especializada Interamericana sobre Derechos Humanos: Actas y Documentos, OEA/Ser.K/XVI/1.2, San José, Costa Rica, 7-22 de noviembre de 1969, Secretaría de la Comisión Interamericana de Derechos Humanos, Washington, D.C., 1973, pp. 38 y 40.

${ }^{21}$ Carozza y González, cit. (n. 6), p. 438.

${ }^{22}$ Ferrer Mac-Gregor, cit. (n. 3), p. 63.

${ }^{23}$ Énfasis añadido.
} 
una de las medidas "de otro carácter" adoptadas para dar efecto a los derechos y libertades de la Convención. ${ }^{24}$ Sin embargo, el mismo artículo 2 dispone que los Estados deben hacer esto de acuerdo con sus "procedimientos constitucionales", los que difícilmente se refieren al control de convencionalidad. Además, el artículo 2 no exige que los titulares del control de convencionalidad evalúen si las disposiciones internas se ajustan a la interpretación de la Corte Interamericana de Derechos Humanos. En consecuencia, la innovadora interpretación de la Corte es demasiado expansiva en su alcance, como veremos luego al describir las complejidades de la doctrina del control de convencionalidad.

Algunos podrían erradamente pensar que la creación de la doctrina del control de convencionalidad se ampara en el poder de la Corte de interpretar la $\mathrm{CADH}$ en forma evolutiva. Sin embargo, la creación de una doctrina como el control de convencionalidad no equivale a interpretar los derechos de manera evolutiva. En efecto, la interpretación de las normas a aplicar en un caso concreto forma parte de las responsabilidades de un juez; en cambio, la definición de los efectos de las sentencias de un tribunal -particularmente dentro de la esfera doméstica de los Estados-forma parte del ámbito de competencia del legislador (en este caso, de los Estados miembros de la CADH).

La Corte también ha extendido el control de convencionalidad a áreas que sobrepasan el propósito original de dicha doctrina. Por ejemplo, en una resolución sobre supervisión de cumplimiento de la sentencia Gelman vs. Uruguay, la Corte dictaminó que el control de convencionalidad tenía un rol significativo en la implementación de las medidas impuestas en sus fallos, especialmente cuando las reparaciones ordenadas por la Corte establecieran medidas que deben ser cumplidas por las judicaturas nacionales. ${ }^{25}$ Sin embargo, la implementación de las medidas impuestas en un fallodesfavorable a un Estado Parte difiere de la directa aplicación interna de la jurisprudencia del Tribunal, pues la primera dice relación con las reparaciones, mientras que la segunda se refiere a la interpretación de las normas de la $\mathrm{CADH}$. En cuanto a las primeras, siempre se ha entendido que la implementación interna de las medidas establecidas por las sentencias de la Corte depende de la legislación de los Estados. De hecho, la CADH dispone en el artículo 68.2 que "la parte del fallo que disponga indemnización compensatoria se podrá

\footnotetext{
${ }^{24}$ Por ejemplo, GonzÁlez, cit. (n. 15), p. 67.

${ }^{25}$ Corte IDH, 20 de marzo de 2013, Gelman v. Uruguay, Supervisión de Cumplimiento de Sentencia, Resolución de la Corte, párr. considerando 73.
} 
ejecutar en el respectivo país por el procedimiento interno vigente para la ejecución de sentencias contra el Estado". ${ }^{26}$ Por lo tanto, causa perplejidad ver esta asociación entre el control de convencionalidad y la implementación automática de sentencias a nivel nacional.

El control de convencionalidad es creado mediante un obiter dicta de la Corte Interamericana y pretende ser vinculante para los Estados. Esto es desconcertante, pues los obiter dicta de la Corte solo puede tener autoridad vinculante si los Estados se los otorgan. ${ }^{27}$ En otras palabras, atendido que la $\mathrm{CADH}$ no dice nada al respecto, la autoridad de la Corte para crear Derecho que modifique las regulaciones internas de los Estados o su forma de incorporación del Derecho internacional solo podría existir si estos mismos Estados otorgan a las sentencias de la Corte dicho poder. Ello es así porque, según la $\mathrm{CADH}$, los Estados miembros están solo obligados a "cumplir la decisión de la Corte en todo caso en que sean partes", ${ }^{28}$ no todas las sentencias de la Corte, ni cualquiera sea su contenido. Distinto sería si la $\mathrm{CADH}$ contuviera una norma que le dé a la jurisprudencia de la Corte un valor vinculante para todos los Estados miembros de la $\mathrm{CADH}$, como ocurre, por ejemplo, con una norma del Estatuto de la Corte Centroamericana de Justicia, que establece que "su doctrina tendrá efectos vinculantes para todos los Estados, órganos y organizaciones que formen parte o participen en el Sistema de la Integración Centroamericana, y para sujetos de derecho privado". ${ }^{29}$

\subsection{Desarrollos académicos de la doctrina}

Los académicos latinoamericanos han profundizado sobre el control de convencionalidad, proponiendo definiciones, afirmando sus supuestas fuentes legales y desarrollando muchos otros elementos. Algunos trabajos académicos tienen una fe dogmática en el control de convencionalidad,

\footnotetext{
${ }^{26}$ Algunos Estados no tienen normas internas en la materia, pero otros, como Perú o Costa Rica, tienen leyes que lo regulan. V. Ley que Regula el Procedimiento de Ejecución de Sentencias Emitidas por Tribunales Supranacionales, Ley N²7.775, Perú, 2002; y Convenio para la Sede de la Corte Interamericana de Derechos Humanos, Ley Nº 6889, Costa Rica, 1983, Art. 1(27).

${ }^{27}$ Solo las constituciones nacionales pueden otorgar a la jurisprudencia de la Corte Interamericana la calidad de ser una fuente de derecho vinculante. HenríQuez Viñas, Miriam Lorena, "La Polisemia del Control de Convencionalidad Interno", International Law. Revista Colombiana de Derecho Internacional, 2014, Vol. 24, p. 129.

${ }^{28} \mathrm{CADH}$, art. 68.1.

${ }^{29}$ Estatuto de la Corte Centroamericana de Justicia, Art. 3.
} 
y debido a ello, no ven ningún inconveniente en esta doctrina ${ }^{30}$ Además, no suele cuestionarse si la fuente del control de convencionalidad son las sentencias de la Corte, ni si éstas fueron emitidas dentro del ámbito de su competencia. Esta última cuestión es fundamental, pues como sabemos, los jueces no pueden emitir resoluciones vinculantes más allá de su competencia (extra compromissum arbiter nihil facere potest ${ }^{31}$ ).

Entre los desarrollos de la doctrina del control de convencionalidad, algunos académicos sostienen que los jueces nacionales asumen un rol secundario como "jueces interamericanos", 32 ya que serían los primeros órganos encargados de aplicar la CADH y la interpretación que de ella realiza la Corte Interamericana. ${ }^{33}$ Algunos autores también han propuesto diferentes clasificaciones del control de convencionalidad, por ejemplo: el control de convencionalidad concentrado sería el aplicado por la Corte Interamericana, y el control de convencionalidad difuso sería el realizado por parte de los órganos nacionales $;{ }^{34}$ el control de convencionalidad débil requeriría interpretar la legislación nacional de acuerdo con la $\mathrm{CADH}$ y la jurisprudencia de la Corte, mientras que el control de convencionalidad fuerte permitiría derogar o anular una ley interna en contradicción con la jurisprudencia de la $\operatorname{Corte}^{35}$ (a menudo nos referiremos a esta distinción en este artículo); el control de convencionalidad primario (o interno) sería el ejercido por los órganos nacionales, y el control de convencionalidad

\footnotetext{
${ }^{30}$ Estos autores podrían equipararse, de alguna manera, a los que Burgorgue-Larsen llama "autores entusiastas". Burgorgue-Larsen, Laurence, "Chronicle of a Fashionable Theory in Latin America. Decoding the Doctrinal Discourse on Conventionality Control", en: Haeck, Y.; Ruiz-Chiriboga, O.; Burbano, C. (eds.), The Inter-American Court of Human Rights: Theory and Practice, Present and Future, Intersentia, Cambridge, 2015, pp. 665-669 (Traducción del autor).

${ }^{31}$ Cheng, Bin, General Principles of Law as Applied by International Courts and Tribunals, ed. reimpresión, Cambridge University Press, Cambridge, 2006, p. 261.

${ }^{32}$ Corte IDH, 26 de noviembre de 2010, Cabrera García y Montiel Flores v. México, Excepciones Preliminares, Fondo, Reparaciones y Costas, Sentencia (ser. C) № 220, voto concurrente párr. 24. Ferrer Mac-Gregor, Eduardo, "Conventionality Control: The New Doctrine of the Inter-American Court of Human Rights", AJIL Unbound, 2015, N 109, p. 97. La Corte Suprema de Chile ha adoptado esta visión, al afirmar que "mediante el control de convencionalidad, los jueces nacionales forman parte del sistema interamericano en la protección de los estándares de cumplimiento y garantía de tales derechos". Corte Suprema de Chile, 16 de mayo de 2019, Rol № AD-1386-2014, considerando $9^{\circ}$.

${ }^{33}$ Ferrer Mac-Gregor, cit. (n. 3), p. 63.

${ }^{34}$ Corte IDH, 26 de noviembre de 2010, Cabrera García y Montiel Flores v. México, Excepciones Preliminares, Fondo, Reparaciones y Costas, Sentencia (ser. C) $N^{\circ} 220$, voto concurrente del juez Ferrer Mac-Gregor, párr. 22.

${ }^{35}$ Contreras VÁsquez, Pablo, “Análisis Crítico del Control de Convencionalidad”, en: Núñez, M. (ed.), La Internacionalización del Derecho Público, Thomson Reuters - La Ley, Santiago, 2015, p. 426.
} 
subsidiario (o internacional o externo) sería el realizado por la Corte Interamericana; ${ }^{36}$ etc.

Algunos consideran que el rol principal de la Corte Interamericana, esto es, determinar si un Estado violó la $\mathrm{CADH}$ o algún otro instrumento sobre el cual la Corte tenga jurisdicción, es una forma de ejercer el control de convencionalidad (esta acción es a menudo llamada "control de convencionalidad concentrado"). ${ }^{37}$ La Corte también ha extendido su doctrina del control de convencionalidad a las interpretaciones que hace en sus opiniones consultivas, las que serían una especie de "control de convencionalidad preventivo". ${ }^{38}$

Uno de los desarrollos más importantes de la doctrina del control de convencionalidad fue realizado por la propia Corte. Dos meses después del primer caso en que ella se refirió al control de convencionalidad, pareció restringir el alcance de esta doctrina. En Aguado Alfaro y otros v. Perú (Trabajadores Cesados del Congreso), el Tribunal declaró que los órganos internos deben ejercer el control de convencionalidad "en el marco de sus respectivas competencias y de las regulaciones procesales correspondientes". ${ }^{39}$ Desde entonces, la Corte Interamericana ha repetido esta declaración, aunque ésta no es clara, especialmente si se analiza junto

\footnotetext{
${ }^{36}$ Instituto Interamericano de Derechos Humanos, Manual Auto-Formativo para la Aplicación del Control de Convencionalidad Dirigido a Operadores de Justicia, Instituto Interamericano de Derechos Humanos, San José de Costa Rica, 2015, pp. 63 y 105. Los nombres alternativos se toman de HenríQuez, cit. (n. 27), p. 116.

37 Por ejemplo, Instituto Interamericano de Derechos Humanos, cit. (n. 36), pp. 105-109. Esta concepción podría haberse originado en el voto razonado de García Ramírez en el caso Aguado Alfaro, en que afirmó: "existe un 'control de convencionalidad' depositado en tribunales internacionales - $\mathrm{O}$ supranacionales-creados por convenciones de aquella naturaleza, que encomienda a tales órganos de la nueva justicia regional de los derechos humanos interpretar y aplicar los tratados de esta materia y pronunciarse sobre hechos supuestamente violatorios de las obligaciones estipuladas en esos convenios, que generan responsabilidad internacional para el Estado que ratificó la convención o adhirió a ella". Corte IDH, 24 de noviembre de 2006, Aguado Alfaro y otros v. Perú (Trabajadores Cesados del Congreso), Excepciones Preliminares, Fondo, Reparaciones y Costas, Sentencia (ser. C) $N^{\circ} 158$, voto razonado del juez Sergio García Ramírez, párr. 5.

${ }^{38}$ Corte IDH, 26 de febrero de 2016, Titularidad de derechos de las personas jurídicas en el sistema interamericano de derechos humanos (Interpretación y alcance del artículo 1.2, en relación con los artículos 1.1, 8, 11.2, 13, 16, 21, 24, 25, 29, 30, 44, 46 y 62.3 de la Convención Americana sobre Derechos Humanos, asi como del artículo 8.1. A y B del Protocolo de San Salvador), Opinión Consultiva OC-22/16 (ser. A) $\mathrm{N}^{\circ} 22$, párr. 26.

${ }^{39}$ Corte IDH, 24 de noviembre de 2006, Aguado Alfaro y otros v. Perú (Trabajadores Cesados del Congreso), Excepciones Preliminares, Fondo, Reparaciones y Costas, Sentencia (ser. C) N 158, párr. 128; Corte IDH, 23 de noviembre de 2010, Vélez Loor v. Panamá, Excepciones Preliminares, Fondo, Reparaciones y Costas, Sentencia (ser. C) N²18, párr. 287.
} 
con el resto de las decisiones de la Corte que definen la doctrina. Debido a esta falta de claridad, esta afirmación ha dado lugar a diferentes formas de entender el control de convencionalidad.

En las siguientes secciones nos referiremos a dos formas diferentes de interpretar la frase antes mencionada, y explicitaremos complejidades específicas que presentan cada una de ellas. Sin embargo, antes de hacerlo mencionaremos algunos problemas que comparten ambos enfoques sobre el control de convencionalidad, a saber:

a) Que los Estados estarían obligados por lo que decidió la Corte Interamericana en casos en los que ellos no fueron oídos como parte..$^{40}$ Esto violaría el principio de bilateralidad de la audiencia, que es sagrado para todo tribunal.

b) Que al interpretar la $\mathrm{CADH}$, la Corte suele utilizar instrumentos internacionales, de distinta naturaleza, ajenos a la Convención. Podría llegar a ser aceptable emplear tratados distintos a la CADH cuando la Corte decida casos contra Estados que los han ratificado. Sin embargo, es inaceptable exigir a los Estados que no han ratificado estos tratados, que apliquen las interpretaciones que la Corte alcanzó utilizándolos. La doctrina del control de convencionalidad podría tener este resultado inadmisible, al exigir a los Estados que apliquen las interpretaciones que la Corte Interamericana alcanzó en casos contra otros Estados, en los cuales puede haber aplicado tratados ajenos a la CADH.

c) Que la Corte Interamericana no sigue un sistema de precedentes, y no es absolutamente consistente en su interpretación de la $\mathrm{CADH} .{ }^{41}$ Esto dificulta que los Estados apliquen el control de convencionalidad, el que requiere no solo aplicar la $\mathrm{CADH}$, sino que también la interpretación que de ella realiza la Corte Interamericana.

d) Que algunos autores consideran que la doctrina del control de convencionalidad es contraria al principio de subsidiariedad, ${ }^{42}$ aunque otros estiman exactamente lo contrario. ${ }^{43}$

\footnotetext{
${ }^{40}$ SAGÜÉs, Nestor Pedro, "Derecho Internacional y Derecho Constitucional. Dificultades Operativas del Control de Convencionalidad en el Sistema Interamericano", en: Ahrens, H. (ed.), El Estado de Derecho Hoy en América Latina. Libro en Homenaje a Horst Schönbohm, GIZ - Konrad Adenauer Stiftung, Berlín - México, D.F., 2012, p. 29.

${ }^{41}$ Ibid., pp. 92 y 93.

${ }^{42}$ Dulitzky, cit. (n. 1), p. 47, y Maino, Carlos Alberto Gabriel, "El Control de Convencionalidad y las Dificultades que Ofrecen las Interpretaciones de la CIDH”, Prudentia Iuris, 2016, N 81, pp. 36-37.

${ }^{43}$ Por ejemplo, Burgorgue-Larsen, cit. (n. 30), p. 658, o Agullar Cavallo, Gonzalo, "El Control de
} 


\section{EL ENFOQUE EXTENSIVO}

\subsection{Cuestiones preliminares}

Se ha afirmado que la expresión "en el marco de sus respectivas competencias y de las regulaciones procesales correspondientes" no restringe el ámbito de aplicación del control de convencionalidad. ${ }^{44}$ Ello implicaría que los órganos nacionales deberían llevar a cabo el control de convencionalidad, incluso si no poseen una facultad constitucional expresa para hacerlo (o para ejercer un control de constitucionalidad de las leyes). Entre estos autores encontramos a Allan Brewer Carías, quien considera que la expresión "en el marco de..." significa que los órganos nacionales deben ejercer el control de convencionalidad "de acuerdo con su competencia por la materia, el grado y el territorio que tengan en el ámbito interno". ${ }^{45}$ Él piensa que no se debe tener en cuenta si los Estados cuentan con un sistema difuso o concentrado de control de constitucionalidad, ni si los jueces tienen la facultad de aplicar directamente la $\mathrm{CADH} .{ }^{46}$

Un ejemplo de esta forma de entender la expresión de la Corte sería la siguiente: si alguien desea que una ley de amnistía nacional sea declarada nula -según la jurisprudencia de la Corte Interamericana al respecto ${ }^{47}-$, tendría que comparecer ante un tribunal que es competente para juzgar al ofensor, es decir, un tribunal penal (competente según la materia) de primera instancia (competente según el grado) y ubicado en el área donde se cometió el delito (competente según el territorio, si ésta es la regla aplicable). Por el contrario, la persona que desea que se declare nula esta ley de amnistía no puede comparecer ante un tribunal de familia, porque este órgano no tiene competencia según la materia. Otro ejemplo sería el de una persona

Convencionalidad: Análisis en Derecho Comparado", Revista Direito GV, 2013, Vol. 9 (18), № 2, p. 731. Otros consideran que la doctrina existe dentro de un sistema que presupone la subsidiariedad. GARCíA, cit. (n. 8), p. 25.

${ }^{44}$ Por ejemplo, Brewer CARÍAs, Allan R., El Control de Convencionalidad, con Particular Referencia a la Garantía del Derecho a la Protección Judicial Mediante un Recurso Sencillo, Rápido y Efectivo de Amparo de los Derechos Humanos, 2012, disponible en línea: http://allanbrewercarias.com/wpcontent/uploads/2012/09/1107-1-1055-EL-CONTROL-DE-CONVENCIONALIDAD-por-la-CorteIDH-Y-AMPARO-18-sept.-2012.doc.pdf, fecha de visita 16 de noviembre de 2018, p. 17.

${ }^{45}$ Ibid.

${ }^{46}$ Ibid., p. 19.

${ }^{47}$ V. Binder, Christina, "The Prohibition of Amnesties by the Inter-American Court of Human Rights", German Law Journal, 2011, Vol. 12, № 5. 
que desee obtener una pensión de sobrevivencia de su pareja homosexual fallecida -de acuerdo con la jurisprudencia de la Corte Interamericana ${ }^{48}$, a pesar de que la ley nacional le otorgue este beneficio exclusivamente a las parejas heterosexuales. Dicha persona tendría que solicitar al órgano de seguridad social correspondiente (competente según la materia), ${ }^{49}$ con jurisdicción sobre el domicilio del trabajador que falleció (competente según el territorio), que desestime la normativa interna pertinente y otorgue el beneficio. ${ }^{50}$ La cuestión de si la legislación nacional otorga a ciertos tribunales específicos el poder de invalidar una norma particular sería irrelevante para esta forma de entender el control de convencionalidad.

Otros académicos comparten la posición de Brewer Carías; de hecho, Néstor Sagüés consideró que la mayoría de los académicos -en ese momento- estaban de acuerdo en que no era necesario que los jueces tuvieran la facultad de ejercer el control de constitucionalidad para aplicar el control de convencionalidad, incluso si su aplicación les obligaba a declarar nula una norma interna. ${ }^{51}$ Sagüés menciona, por ejemplo, a Ernesto Rey Cantor. ${ }^{52}$ Nogueira Alcalá es otro autor que consideraría que todos los jueces y los demás órganos que ejercen funciones jurisdiccionales deberían participar en el control de convencionalidad. ${ }^{53}$ Miriam Henríquez, que

${ }^{48}$ Véase Corte IDH, 26 de febrero de 2016, Duque v. Colombia, Excepciones Preliminares, Fondo, Reparaciones y Costas, Sentencia (ser. C) N 310.

${ }^{49}$ Podría decirse que ello sería independientemente de si el órgano es público o privado, pues la Corte Interamericana ha declarado responsables a Estados por violaciones cometidas por empresas privadas, cuando no han sido reparadas por sus tribunales nacionales. V. Corte IDH, 21 de mayo de 2013. Suárez Peralta v. Ecuador, Excepciones Preliminares, Fondo, Reparaciones y Costas, Sentencia (ser. C) $\mathrm{N}^{\circ}$ 261, y Corte IDH, 31 de agosto de 2017, Lagos del Campo v. Perú, Excepciones Preliminares, Fondo, Reparaciones y Costas, Sentencia (ser. C) N 340.

${ }^{50}$ En este ejemplo no habría necesidad de distinguir según el grado.

${ }^{51}$ SAgüÉs, Nestor Pedro, "El 'Control de Convencionalidad' en el Sistema Interamericano y sus Anticipos en el Ámbito de los Derechos Económico-Sociales. Concordancias y Diferencias con el Sistema Europeo", http://www.corteidh.or.cr/tablas/r27778.pdf, 16 de noviembre de 2018, pp. 427428. Sin embargo, Sagüés posteriormente parece haber matizado su afirmación: SAGÜÉs, Nestor Pedro, "Obligaciones Internacionales y Control de Convencionalidad", en: Instituto de Justicia Constitucional Corte de Constitucionalidad \& Asociación Cívica Instituto de Gobernanza (eds.), Opus Magna Constitucional Guatemalteca, Instituto de Justicia Constitucional, Guatemala, 2011, p. 276.

${ }^{52}$ SAGÜÉs, Nestor Pedro, “Obligaciones Internacionales y Control del Convencionalidad”, Estudios Constitucionales, 2010, Vol. 8, № 1, p. 121.

${ }^{53}$ Esto se desprende de Nogueira Alcalá, Humberto, "Los Desafíos del Control de Convencionalidad del Corpus Iuris Interamericano para las Jurisdicciones Nacionales", Boletín Mexicano de Derecho Comparado, 2012, Año XLV, Vol. 135, pp. 1175-1178. Nogueira reafirma esto en un trabajo en que sostiene que los tribunales chilenos deben ejercer un control de la convencionalidad fuerte, aunque no puedan realizar el control de constitucionalidad de la legislación. NogueIra Alcalá, Humberto, 
critica la doctrina, estima que la Corte Interamericana intentó ampliar las competencias de todas las autoridades para exigirles que ejerzan el control de convencionalidad. ${ }^{54}$ Ariel Dulitzky, otro académico crítico, considera que la expresión "en el marco de sus respectivas..." es una forma simplista en la que la Corte intenta superar el problema de requerir a los jueces que realicen acciones que van más allá de sus atribuciones constitucionales. ${ }^{55} \mathrm{No}$ solo académicos comparten la posición de Brewer, pues también lo hacen tribunales como la Corte Constitucional de Ecuador, según se observa en una sentencia reciente. ${ }^{56}$

\subsection{La jurisprudencia interamericana y el enfoque extensivo}

En términos generales, la jurisprudencia de la Corte Interamericana apoyaría la interpretación extensiva. ${ }^{57}$ En primer lugar, esto es sugerido por las palabras de la Corte, porque no dispone que los jueces solo deben ejercer el control de convencionalidad si tienen competencia para hacerlo, sino que afirma que ellos deben ejercer el control de convencionalidad dentro de su esfera de competencia. Frente a este razonamiento, es posible contraargumentar que los jueces siempre deben ejercer un control de convencionalidad débil, pero que pueden ejercer un control de convencionalidad fuerte si poseen la facultad de anular o dejar sin aplicación la legislación interna. ${ }^{58}$ Sin embargo, muchas sentencias de la Corte asumen que los tribunales nacionales u otros órganos deberían llevar a cabo un control de convencionalidad fuerte, incluso si no están autorizados legalmente para hacerlo, como lo demostraremos a continuación.

\footnotetext{
"Sistema Interamericano de Protección de Derechos Humanos, Control de Convencionalidad y Aplicación por Parte de las Jurisdicciones Nacionales", en: Nogueira, H. (ed.), La Protección de los Derechos Humanos y Fundamentales de Acuerdo a la Constitución y el Derecho Internacional de los Derechos Humanos, Centro de Estudios Constitucionales de Chile - Librotecnia, Santiago, 2014, p. 405.

${ }^{54}$ Henríquez, cit. (n. 27), p. 125.

${ }^{55}$ Dulitzky, cit. (n. 1), p. 60.

${ }^{56}$ En ella afirma: "El juez y la jueza sí tienen competencias para realizar control de constitucionalidad y de convencionalidad, como cualquier otra autoridad pública en el ámbito de sus competencias. (...) Con relación a si un juez o jueza prevarica por inobservar una norma que considera inconstitucional y aplicar la Constitución, los operadores de justicia no prevarican”. Corte Constitucional del Ecuador, 12 de junio de 2019, Rol N 11-18-CN/19 (matrimonio igualitario), considerando 290.

${ }^{57}$ Dulitzky parece estar de acuerdo con esto cuando afirma que el lenguaje expansivo de la Corte sugiere que adopta la "interpretación absolutista" del control de convencionalidad. Ibid., p. 52 (Traducción del autor).
}

${ }^{58}$ Ferrer Mac-Gregor, cit. (n. 3), pp. 63 y 64. 
El caso Boyce vs. Barbados -fallado después de Aguado Alfaroproporciona el primer ejemplo. Este caso nos muestra que la Constitución de Barbados negaba a los tribunales la competencia para ejercer el control de constitucionalidad de las leyes promulgadas antes del 30 de noviembre de $1966 .{ }^{59}$ Esta prohibición se aplicaba, incluso, a la entonces máxima autoridad judicial de Barbados, el Comité Judicial del Consejo Privado (CJPC), con sede en el Reino Unido. Sin embargo, la Corte Interamericana declaró que "los tribunales de Barbados, incluso el CJCP y ahora la Corte de Justicia del Caribe, deben también decidir si la ley de Barbados restringe o viola los derechos reconocidos en la (CADH)" ${ }^{60}$ incluso si dicha ley fue promulgada antes de 1966. En otras palabras, la Corte se consideró autorizada para otorgar a los tribunales barbadenses la facultad de revisar la convencionalidad de una ley, a la luz de su propia interpretación de la $\mathrm{CADH}$, a pesar de que los tribunales eran incompetentes, y de que esto iba en contra de la Constitución de Barbados. Esta sentencia es particularmente interesante, porque afectó a un Estado dualista, es decir, uno que, siguiendo la tradición británica, requiere la incorporación de los tratados internacionales antes de que puedan tener efectos internos. En este caso en particular, el comportamiento de la Corte fue displicente respecto al enfoque dualista del Derecho internacional. En efecto, la Corte no ignoraba que la legislación de Barbados no había incorporado la doctrina del control de convencionalidad, pero eso no le impidió exigirle a Barbados que actuara de acuerdo con ella.

La sentencia Boyce no fue solo un fallo aislado, pues hay otros ejemplos similares. El enfoque extensivo de la Corte Interamericana también se nota en situaciones donde ella decide que las leyes de amnistía son "incompatibles ab initio" con la $\mathrm{CADH},{ }^{61}$ y que debido a ello, "dichas 'leyes' no han podido generar efectos, no los tienen en el presente ni podrán generarlos en el futuro". ${ }^{62}$ En otras palabras, la Corte declara que estas leyes

\footnotetext{
${ }^{59}$ Corte IDH, 20 de noviembre de 2007, Boyce y otros v. Barbados, Excepción Preliminar, Fondo, Reparaciones y Costas, Sentencia (ser. C) № 169, párr. 75.

${ }^{60}$ Ibid., párr. 78. Además, la Corte afirmó que la decisión del CJCP fue alcanzada "a través de un análisis puramente constitucional, en el cual no se tuvo en cuenta las obligaciones que tiene el Estado conforme a la Convención Americana y según la jurisprudencia de esta Corte”. Ibid., párr. 77. La Corte también declaró: "El análisis del CJCP no debería haberse limitado a evaluar si la (ley pertinente) era inconstitucional. Más bien, la cuestión debería haber girado en torno a si la ley también era 'convencional'”. Ibid., párr. 78.

${ }^{61}$ Corte IDH, 29 de noviembre de 2006, La Cantuta v. Perú, Fondo, Reparaciones y Costas, Sentencia (ser. C) $\mathrm{N}^{\circ} 162$, párr. 189.

${ }^{62}$ Ibid.
} 
son nulas, lo que implica que la Corte Interamericana se está otorgando el poder de ejercer el control judicial sobre la legislación de las jurisdicciones nacionales. Dicho de otro modo, los tribunales nacionales no tendrían necesidad de invalidar estas leyes, porque la propia Corte Interamericana las declara nulas. Del mismo modo, en Radilla Pacheco vs. México la Corte dispuso que las leyes contrarias al objeto y propósito de la CADH carecen de efecto desde el momento de su promulgación. ${ }^{63}$ Esto es consistente con lo sucedido en Almonacid vs. Chile, donde la Corte Interamericana declaró que el Poder Judicial debería negarse a aplicar la Ley de Amnistía, ${ }^{64}$ a pesar de que en Chile el Tribunal Constitucional es el único órgano que puede ejercer el control de constitucionalidad y dejar una ley sin aplicación. ${ }^{65}$

Otro ejemplo es uno donde la Corte, sin referirse expresamente a la doctrina del control de convencionalidad, busca que sus fallos tengan un efecto inmediato a nivel nacional, aunque ello contraríe la normativa interna. Este ejemplo se relaciona con la sentencia del caso Artavia Murillo vs. Costa Rica, donde la Corte Interamericana declaró que la prohibición de la técnica de fertilización in vitro (FIV) era contraria a la CADH ${ }^{66}$ Tras esta decisión, el gobierno costarricense promovió la aprobación de proyectos de ley que regulaban el asunto, pero la Asamblea Legislativa no adoptó la nueva legislación. Posteriormente, el Ejecutivo intentó aprobar la FIV mediante la promulgación de un decreto, pero la Corte Suprema de Costa Rica lo declaró inválido por violar el principio de legalidad y el principio democrático ${ }^{67} \mathrm{y}$ señaló que sólo la Asamblea Legislativa tenía derecho a aprobar legislación relativa a la FIV. ${ }^{68}$ Posteriormente, cuando la Corte Interamericana supervisó el cumplimiento de Artavia Murillo, decidió que el modo de proceder de Costa Rica era inadecuado, ya que el fallo de Artavia Murillo tenía el efecto inmediato de autorizar la FIV en dicho Estado. ${ }^{69}$ También declaró

\footnotetext{
${ }^{63}$ Corte IDH, 23 de noviembre de 2011, Radilla Pacheco v. México, Excepciones Preliminares, Fondo, Reparaciones y Costas, Sentencia (ser. C) N²09, párr. 339.

${ }^{64}$ Corte IDH, 26 de septiembre de 2006, Almonacid Arellano y otros v. Chile, Excepciones Preliminares, Fondo, Reparaciones y Costas, Sentencia (ser. C) № 154, párrs. 123 \& 124.

${ }^{65}$ Constitución Política de la República de Chile, Art. 93.

${ }^{66}$ Corte IDH, 28 de noviembre de 2012, Artavia Murillo y otros ("fertilización in vitro") v. Costa Rica, Excepciones Preliminares, Fondo, Reparaciones y Costas, Sentencia (ser. C) № 257.

${ }^{67}$ Corte Suprema de Costa Rica, 3 de febrero de 2016, Exp. 15-013929-0007-CO, Sentencia N ${ }^{\circ} 01692-$ $16, \mathrm{~V}$.

${ }^{68}$ Ibid.

${ }^{69}$ Corte IDH, 26 de febrero de 2016, Artavia Murillo y otros v. Costa Rica, Supervisión de Cumplimiento de Sentencia, Resolución de la Corte, párr. "considerando que”, 26.
} 
que el decreto anulado por la Corte Suprema debía considerarse válido, para que la FIV pudiera realizarse fácilmente. ${ }^{70}$ Estas decisiones de la Corte Interamericana fueron bastante más allá del propósito de una resolución de supervisión de cumplimiento. Sin embargo, lo que es más importante para nuestro análisis, es que demuestra que a la Corte no le preocupan las normas internas que establecen competencia y requisitos de procedimiento.

Liakat Ali Alibux v. Surinam también es revelador. En este caso, la Corte Interamericana dictaminó que no imponía a los Estados la obligación de contar con tribunales constitucionales, y que la CADH "no impone un modelo específico para realizar un control de constitucionalidady convencionalidad". ${ }^{71}$ Sin embargo, la Corte Interamericana recordó que "la obligación de ejercer un control de convencionalidad entre las normas internas y la Convención Americana le compete a todos los órganos del Estado, incluidos sus jueces y demás órganos vinculados a la administración de justicia en todos los niveles". ${ }^{72}$ En otras palabras, parece dictaminar que, independientemente de que el Estado establezca o no un Tribunal Constitucional, todos sus órganos están igualmente obligados a llevar a cabo el control de convencionalidad (probablemente, incluso, un control de convencionalidad fuerte). Algunos autores piensan distinto, y afirman que esta declaración de la Corte significa que los Estados son libres de determinar si sus órganos internos -y cuáles de estos órganos- deben realizar el control de convencionalidad (fuerte o débil). ${ }^{73}$ Sería deseable que ésta fuera la lectura correcta de las sentencias de la Corte. Sin embargo, no existe ninguna resolución o declaración explícita del Tribunal que respalde dicha lectura.

Por último, podría argumentarse que, si la Corte considera que los órganos nacionales deben seguir las decisiones interamericanas, incluso si ello implica invalidar normas sustantivas internas, no parecería haber razón para que la Corte esté tan interesada en que dichos órganos cumplan con normas procesales internas que se erigen como obstáculo para aplicar sus decisiones. Ello es aún más así, si se considera que, en más de alguna ocasión, la Corte ha afirmado -aunque refiriéndose a otra materia- que la

\footnotetext{
${ }^{70}$ Ibid., párr. "considerando que" 36.

${ }^{71}$ Corte IDH, 30 de enero de 2014, Liakat Ali Alibux v. Suriname, Excepciones Preliminares, Fondo, Reparaciones y Costas, Sentencia (ser. C) N²76, párr. 124.

${ }^{72}$ Ibid.

${ }^{73}$ GonZÁlez, cit. (n. 15), p. 74.
} 
justicia "no puede ser sacrificada en aras de meras formalidades". ${ }^{74}$

\subsection{Complejidades del enfoque extensivo}

El enfoque extensivo de la doctrina del control de convencionalidad revela serias dificultades. Esto explica por qué ciertos académicos y tribunales nacionales se oponen a dicha doctrina. ${ }^{75}$ Los académicos han descrito las desventajas del control de convencionalidad en cierto detalle. ${ }^{76}$ Algunos problemas del enfoque extensivo (que no padecen los enfoques acotados) son los siguientes:

a) La CADH no establece el control de convencionalidad. Incluso aquellos que consideran que dicha doctrina está fundamentada legalmente, como el juez Ferrer Mac-Gregor, solo son capaces de señalar un grupo de disposiciones que conjuntamente-y en forma poco convincente- establecerían la base legal de tal doctrina. ${ }^{77}$ Como resultado de esta falta de fundamento legal, la Corte violaría el principio extra compromissum arbiter nihil facere potest (el "principio de competencia") ${ }^{78}$ al crear el control de convencionalidad.

b) Al crear la doctrina del control de convencionalidad (si se sigue el enfoque extensivo), la Corte Interamericana se designaría a sí misma como un tribunal supranacional cuyas decisiones deben ser seguidas por los órganos nacionales, aun cuando los Estados no hayan dado su consentimiento para ello. ${ }^{79}$

${ }^{74}$ V/gr., Corte IDH, 3 de febrero de 1993, Cayara v. Perú, Excepciones Preliminares, Sentencia (ser. C) $\mathrm{N}^{\circ} 14$, párr. 42.

${ }^{75}$ Ejemplos seleccionados de la literatura académica incluyen: Silva Aввот, Max, "Control de Convencionalidad Interno y Jueces Locales: Un Planteamiento Defectuoso", Estudios Constitucionales, 2016, Vol. 14, N 2; Dulitzky, cit. (n. 1); Castilla, cit. (n. 6); Malarino, Ezequiel, "Acerca de la Pretendida Obligatoriedad de la Jurisprudencia de los Órganos Interamericanos de Protección de Derechos Humanos para los Tribunales Judiciales Nacionales", en: Steiner, C. (ed), Sistema Interamericano de Protección de los Derechos Humanos y Derecho Penal Internacional, Konrad-Adenauer-Stiftung e. V., Montevideo, 2011. Ejemplos de jurisprudencia contraria al control de convencionalidad: Suprema Corte de Justicia de Uruguay, 22 de febrero de 2013, "M. L., J. F. F., O. - Denuncia - Excepción de Inconstitucionalidad Arts. 1, 2 y 3 de la Ley Nro. 18.831", IUE 2-109971/2011, Sentencia, III" (pp. 12-24). Véase también Corte Suprema de Justicia de la Nación Argentina, 14 de febrero de 2017, "Fontevecchia y D'Amico vs. Argentina", Sentencia, párrs. 6-14 (donde la Corte Suprema de Argentina incluso cuestiona si estaría obligada a revertir una decisión basada en una ley de amnistía).

${ }^{76}$ Ibid.

${ }^{77}$ Ferrer Mac-Gregor, cit. (n. 32), p. 96.

${ }^{78}$ Cheng, cit. (n. 31), p. 261. Este principio "requiere que un tribunal decida estrictamente de acuerdo con las normas de su Constitución, so pena de nulidad", Ibid. (traducción del autor).

${ }^{79}$ En palabras de Dulitzky, el control de la convencionalidad "coloca a la Convención Americana 
c) La Corte concedería a los órganos nacionales, por vía jurisprudencial, el poder de revisar la "convencionalidad" de la normativa interna. Esto violaría el principio de legalidad, puesto que los órganos de los Estados pueden hacer sólo aquello que se les permite por la vía legal, no jurisprudencial. ${ }^{80}$

d) El enfoque extensivo soslaya que solamente el Estado tiene el poder de decidir la relación entre su orden jurídico interno y el Derecho internacional.

e) Al formular la doctrina, la Corte no se plantea siquiera que en la $\mathrm{CADH}$ pudiera haber normas que no fueran autoejecutables o self-executing. ${ }^{81}$

f) El control de convencionalidad asume que la $\mathrm{CADH}$ tiene un rango más alto que cualquier norma nacional -en el ámbito interno- incluida la Constitución del Estado. ${ }^{82}$ Esto iría en contra del Estado de Derecho, ${ }^{83}$ ya que los órganos nacionales están obligados a seguir, en primer lugar, lo que establece su propia Constitución.

g) Otorga a las interpretaciones de la Corte Interamericana el mismo rango que a las disposiciones de la $\mathrm{CADH}$, a pesar de que la Corte no es la intérprete auténtica de este tratado. ${ }^{84}$

h) "(A)dopta un enfoque radicalmente monista de la relación entre el

y a su intérprete judicial interamericano, la Corte, en la parte superior del ordenamiento jurídico." DulitZKY, cit. (n. 1), p. 47 (traducción del autor). Del mismo modo, el control de convencionalidad, "al exigir que los jueces nacionales apliquen la Convención Americana sobre la legislación nacional según la interpretación de la Corte, posiciona a la Corte Interamericana como una especie de corte constitucional interamericana." Ibid., p. 48 (traducción del autor).

${ }^{80}$ CAndia-Falcón, Gonzalo, "El Estado de Derecho y la Corte Interamericana de Derechos Humanos", Díkaion, 2015, Vol. 24, $\mathrm{N}^{\circ}$ 2, pp. 244-245.

${ }^{81}$ Sobre las obligaciones autoejecutables, sus interpretaciones y la dificultad de su definición, véase Pisillo Mazzeschi, Riccardo, "Responsabilité de l'État pour Violation des Obligations Positives Relatives aux Droits de l'Homme", Recueil des Cours (Académie de Droit International), 2008, $\mathrm{N}^{\circ}$ 333, pp. 256-264.

${ }^{82}$ SAGÜÉs, cit. (n. 52), pp. 124-125.

${ }^{83}$ La primera vez que la Corte mencionó la expresión control de convencionalidad, la planteó como una especie de excepción al Estado de Derecho interno. Corte IDH, 26 de septiembre de 2006, Almonacid Arellano y otros v. Chile, Excepciones Preliminares, Fondo, Reparaciones y Costas, Sentencia (ser. C) $\mathrm{N}^{\circ} 154$, párr. 124. El concepto de Estado de Derecho es más bien controvertido. El Black's Law Dictionary da estas dos definiciones pertinentes: "La supremacía del poder regular en oposición al poder arbitrario; la ausencia de todo poder arbitrario por parte del gobierno", y "[1]a doctrina en virtud de la cual toda persona está sujeta al Derecho corriente dentro del territorio; la igual subordinación de todos los ciudadanos y clases al derecho común del Estado". GARner, Bryan A. (ed), Black's Law Dictionary, Thomson Reuters, Minnesota, 2014, 10ª ed., p. 1531 (traducción del autor).

${ }^{84}$ La Corte es solo la intérprete de la CADH en casos específicos, no la única y última intérprete de la Convención en general. Los intérpretes auténticos de la CADH son los propios Estados. Véase PAÚL, Álvaro, "Cuatro Extendidos Desaciertos de la Corte Interamericana que se Observan en su Opinión Consultiva $\mathrm{N}^{\circ} 24$ " en: Facultad de Derecho Universidad Diego Portales (eds.), Anuario de Derecho Público 2018, Ediciones Universidad Diego Portales, Santiago, 2018, pp. 212-214. 
Derecho internacional y el nacional". ${ }^{85}$ Esto es particularmente complejo en el continente americano, donde un tercio de los Estados independientes son dualistas en relación con los tratados internacionales. ${ }^{86}$ Los Estados dualistas no aceptarían un enfoque extensivo de la doctrina del control de convencionalidad. ${ }^{87}$

i) La Corte no está sujeta a un sistema adecuado de controles en su deber de interpretar la CADH. Por ello, la adopción del enfoque extensivo del control de convencionalidad otorgaría a la Corte el poder de un legislador absoluto.

j) La aplicación de un enfoque extensivo del control de convencionalidad sería incoherente en Estados donde solo uno o unos pocos tribunales pueden ejercer el control de constitucionalidad. En tales Estados, la mayoría de los tribunales no tendrían competencia para evaluar la constitucionalidad de las normas (a pesar de que ellos están familiarizados con su propia Constitución), pero se les otorgaría la facultad de determinar la "convencionalidad" de las mismas en relación con la CADH (a pesar de que generalmente no están al tanto de los desarrollos de la jurisprudencia interamericana).

k) La Corte Interamericana de Derechos Humanos ha fallado que los privados pueden violar la $\mathrm{CADH}$, y que los tribunales nacionales deben reparar tales abusos. ${ }^{88}$ Algunas de tales violaciones se cometen cuando los privados prestan servicios públicos, como salud y educación superior. En dichas áreas puede haber algunas leyes que contradigan la CADH o la interpretación que de ella realiza la Corte Interamericana. Como resultado, si seguimos hasta sus conclusiones lógicas la interpretación extensiva del

${ }^{85}$ BINDER, cit. (n. 47), p. 1204 (la traducción es nuestra). Nosotros entendemos las complejidades de la distinción entre la incorporación monista y dualista del Derecho internacional, pero utilizamos esta distinción porque su simplicidad hace que la complejidad del control de convencionalidad sea más fácil de entender.

${ }^{86}$ Principalmente países angloparlantes del Caribe. Antorne, Rose-Marie Belle, Commonwealth Caribbean Law and Legal Systems, Routledge-Cavendish, New York, 2008, 2ª ed., p. 217.

${ }^{87}$ No sería aceptable porque los dualistas enfatizan "que las reglas de los sistemas de Derecho internacional y nacional existen por separado y no pueden pretender tener un efecto sobre el otro o anularlo" (SHAw, Malcolm N., International Law, Cambridge University Press, Cambridge - New York, $8^{\mathrm{a}}$ ed., 2017 , p. 97 -traducción del autor). Por lo tanto, la CADH y la interpretación de ella realizada por la Corte solo tendrían efecto en el plano internacional, a no ser que las leyes nacionales les otorgaran algún efecto interno, que es exactamente lo que intentaría superar -al menos en su enfoque extensivola doctrina del control de convencionalidad.

${ }^{88}$ Ver, por ejemplo, Corte IDH, 21 de mayo de 2013, Suárez Peralta v. Ecuador, Excepciones Preliminares, Fondo, Reparaciones y Costas, Sentencia (ser. C) N²61, y Corte IDH, 31 de agosto de 2017, Lagos del Campo v. Perú, Excepciones Preliminares, Fondo, Reparaciones y Costas, Sentencia (ser. C) No 340. 
control de convencionalidad, puede llegar a afirmarse que los privados pueden tener el poder de rechazar legislación que no se ajuste a los estándares interamericanos.

Además de estos puntos, el enfoque extensivo comparte algunos problemas de los enfoques más acotados. Este trabajo describe a continuación los enfoques acotados y sus dificultades.

\section{LOS ENFOQUES ACOTADOS}

\subsection{Descripción general}

El ex juez García Ramírez, iniciador de la doctrina del control de convencionalidad, emitió una opinión separada sobre el caso Aguado Alfaro, donde considera que existe una brecha entre los sistemas legales nacionales e internacionales, y que es posible tender un puente entre ambos órdenes jurídicos. ${ }^{89}$ Esto sucedería "cuando un texto supremo otorga el más alto valor a los tratados internacionales sobre derechos humanos o cuando advierte que prevalecerá, en caso de diferencia o discrepancia, la norma que contenga mayores garantías o más amplios derechos para las personas". ${ }^{90}$ García Ramírez afirma que si esta conexión es "clara y rotunda", o al menos "suficiente, inteligible, que no naufrague en la duda o la diversidad de interpretaciones", y solo entonces, "los tribunales nacionales pueden y deben llevar a cabo su propio "control de convencionalidad"". 91

Estas declaraciones dan a entender que los tribunales nacionales podrían ejercer un control de convencionalidad fuerte si su sistema otorga a la CADH un estatus constitucional. Desafortunadamente, no es posible afirmar que la Corte respaldó la declaración del exjuez García Ramírez, porque las opiniones separadas representan el punto de vista individual de un juez y no son representativas de la comprensión mayoritaria de la Corte en un asunto en particular. ${ }^{92}$ De hecho, el Tribunal nunca ha aclarado qué

\footnotetext{
${ }^{89}$ Corte IDH, 24 de noviembre de 2006, Aguado Alfaro y otros v. Perú (Trabajadores Cesados del Congreso), Excepciones Preliminares, Fondo, Reparaciones y Costas, Sentencia (ser. C) $N^{\circ} 158$, voto separado del juez García Ramírez, párr. 10.

${ }^{90}$ Ibid. (el original habla de "más amplio derechos" -sic-).

${ }^{91}$ Ibid., voto separado del juez García Ramírez, párr. 11.

92 Destacamos esto porque tal noción básica ha sido cuestionada por Laurence Burgorgue-Larsen, quien considera que "los votos concurrentes buscan guiar in fine a los jueces nacionales; buscan refinar,
} 
significa la frase "en el marco de sus respectivas competencias y de las regulaciones procesales correspondientes". Esto permite la existencia de diferentes interpretaciones de la declaración de la Corte.

Algunos académicos consideran que la expresión "en el marco de sus respectivas competencias y de las regulaciones procesales correspondientes" $" 93$ significa que, aunque todos los jueces deben ejercer el control de convencionalidad en su forma débil (interpretar las leyes nacionales de acuerdo con la CADH y la interpretación que de ella haga la Corte), sólo los órganos capacitados para hacer un control de constitucionalidad, pueden ejercer el control de convencionalidad fuerte (rechazar la aplicación de leyes nacionales contrarias a la interpretación de la $\mathrm{CADH}$ efectuada por la Corte $)^{94}$. Esta posición entrelaza el control de convencionalidad con el control de constitucionalidad. Dentro de los autores que sostienen esta postura se encuentran Carozza y González Domínguez, quienes sostienen que éste es el significado del control de convencionalidad desde la decisión Aguado Alfaro. ${ }^{95}$ Más importante aún, algunos jueces de la Corte Interamericana adoptan una opinión similar. El juez Ferrer Mac-Gregor es uno de los principales defensores de esta interpretación, ${ }^{96}$ según describiremos en el párrafo siguiente. El juez Vio Grossi también es favorable a un enfoque acotado, pero probablemente más restringido que el de García Ramírez. Él afirma, simplemente, que la jurisprudencia de la Corte Interamericana

\begin{abstract}
"es vinculante solo para el Estado que se haya comprometido a cumplir la 'decisión de la Corte' en el caso en que sea parte y que para los demás Estados Partes de la Convención es únicamente fuente auxiliar del derecho internacional público, es decir, un 'medio auxiliar para la determinación de las reglas de derecho". ${ }^{97}$
\end{abstract}

explicar y conceptualizar el nuevo rol de los jueces nacionales". BURGORGUE-LARSEN, cit. (n. 30), p. 660 (traducción del autor).

${ }^{93}$ Corte IDH, 24 de noviembre de 2006, Aguado Alfaro y otros v. Perú (Trabajadores Cesados del Congreso), Excepciones Preliminares, Fondo, Reparaciones y Costas, Sentencia (ser. C) $N^{\circ} 158$, párr. 128; Corte IDH, 23 de noviembre de 2010, Vélez Loor v. Panamá, Excepciones Preliminares, Fondo, Reparaciones y Costas, Sentencia (ser. C) N²18, párr. 287.

${ }^{94}$ Carozza; González, cit. (n. 6), p. 439.

95 Íbid.

${ }^{96}$ Ferrer Mac-Gregor, cit. (n. 3), pp. 63-64.

${ }^{97}$ Sic. Corte IDH, 30 de junio de 2015, Wong Ho Wing v. Perú, Excepción Preliminar, Fondo, Reparaciones y Costas, Sentencia (ser. C) $\mathrm{N}^{\circ} 297$, voto disidente del juez Vio Grossi, in fine. Ha sostenido opiniones similares en Corte IDH, 17 de abril de 2015, Cruz Sánchez y otros v. Perú, 
El juez interamericano Eduardo Ferrer Mac-Gregor, en su opinión separada sobre el caso Cabrera y Montiel v. México, parece afirmar que la conexión entre el control de convencionalidad y el control de constitucionalidad se basa en algunas constituciones latinoamericanas que se refieren a tratados de derechos humanos, y en algunas sentencias de los tribunales superiores que han fallado que estos tratados tienen rango constitucional..$^{98}$ De acuerdo con estas constituciones y fallos, la CADH habría adquirido un estatus constitucional en algunos Estados. ${ }^{99}$ Por lo tanto, cuando los órganos nacionales encargados de ejercer el control de constitucionalidad analizan la compatibilidad de las leyes nacionales con sus constituciones, también deberían analizar su compatibilidad con los tratados incorporados en sus constituciones. Ferrer Mac-Gregor también señala que algunas judicaturas nacionales han desarrollado la teoría del "bloque constitucional". ${ }^{100}$ Según esta teoría, los encargados del control de constitucionalidad no solo deberían contrastar las normas legales con la Constitución del Estado, sino también con el "bloque constitucional", que incluiría otras normas con un estatus constitucional. Los jueces pueden considerar que estas normas incluyen algunos tratados y su interpretación por parte de los organismos internacionales pertinentes. Esta sería la razón por la cual Ferrer cree que los órganos con poder para ejercer el control de constitucionalidad también pueden realizar el control de convencionalidad.

Otros autores sostienen que el control de convencionalidad solo se puede aplicar a nivel nacional si existen cláusulas constitucionales que abran las puertas del sistema legal interno al Derecho internacional, y que otorguen a los tratados de derechos humanos una jerarquía constitucional ${ }^{101}$ (estas cláusulas serían los puentes entre ambos órdenes legales, previstos por

Excepciones Preliminares, Fondo, Reparaciones y Costas, Sentencia (ser. C) $N^{\circ} 292$, voto disidente del juez Vio Grossi, in fine, y Corte IDH, 29 de noviembre de 2016, Gómez Murillo y otros v. Costa Rica, Sentencia (ser. C) N 326, voto disidente del juez Vio Grossi, introducción.

${ }^{98}$ Corte IDH, 26 de noviembre de 2010, Cabrera García y Montiel Flores v. México, Excepciones Preliminares, Fondo, Reparaciones y Costas, Sentencia (ser. C) $N^{\circ} 220$, voto concurrente del juez Ferrer Mac-Gregor, párrs. 25 y 26.

${ }^{99}$ Ibid.

${ }^{100}$ Sobre el bloque constitucional, véase HuneEus, Alexandra, "Constitutional Lawyers and the InterAmerican Court's Varied Authority", Law and Contemporary Problems, 2016, Vol. 79, N 1, pp. 186.

${ }^{101}$ Henríquez Viñas, Miriam; NúÑEz Leiva, José Ignacio, "Control de Convencionalidad en Chile. Un Soliloquio en 'El Laberinto de la Soledad"” en: Henríquez, M.; Morales, M. (eds.), El Control de Convencionalidad: Un Balance Comparado a 10 Años de Almonacid Arellano vs. Chile, Ediciones Der, Santiago, 2017, p. 379. 
el juez García Ramírez). Todas estas posiciones acotadas son radicalmente diferentes a la de Brewer Carías, quien considera que la expresión "en el marco de..." no tiene relación con si estos órganos nacionales tienen el poder de ejercer el control de constitucionalidad. ${ }^{102}$

Como podemos ver, hay al menos dos interpretaciones acotadas del control de convencionalidad, que se describen a continuación:

La primera tiende a considerar que, cuando la Corte establece que todas las autoridades de un Estado deben ejercer el control de convencionalidad, ${ }^{103}$ se refiere a que ellas deben ejercer un control de convencionalidad débil, es decir, interpretar la legislación nacional de acuerdo con la CADH. Solo aquellas que tienen la atribución de realizar el control de constitucionalidad estarían facultadas para ejercer un control de convencionalidad fuerte, es decir, dejar de aplicar normas nacionales que sean contrarias a la interpretación que la Corte Interamericana haga de la $\mathrm{CADH}$. Esta posición plantea la existencia de una conexión automática del control de convencionalidad y el de constitucionalidad. Posiblemente esta posición esté influenciada por una interpretación de la Suprema Corte de México, que dispuso que el control de convencionalidad debe realizarse de acuerdo con las regulaciones del control de constitucionalidad. ${ }^{104}$ Esta opinión ha sido adoptada también por otros tribunales nacionales superiores de América, como el Tribunal Constitucional Plurinacional de Bolivia. ${ }^{105}$

La segunda posición no equipara el poder de realizar el control de constitucionalidad con el poder de ejercer un control de convencionalidad fuerte. En efecto, para permitir que los órganos internos que realizan el control de constitucionalidad puedan ejercer el control de convencionalidad, esta posición requeriría el cumplimiento de ciertas condiciones. Los Estados necesitarían tener una norma constitucional o legal que interrelacione sus sistemas jurídicos internos con el Derecho internacional, como podría ser una incorporación constitucional inmediata del Derecho internacional de los derechos humanos. En tales casos, estos órdenes jurídicos tendrían que

\footnotetext{
102 BRewer, cit. (n. 44), p. 17.

${ }^{103}$ Corte IDH, 1 de diciembre de 2016, Andrade Salmón v. Bolivia, Fondo, Reparaciones y Costas, Sentencia (ser. C) $\mathrm{N}^{\circ} 330$, párr. 93.

104 Brewer, cit. (n. 44), p. 17.

${ }^{105}$ Tribunal Constitucional Plurinacional de Bolivia, 28 de noviembre de 2017, 0084/2017, Sentencia, p. 32. Este tribunal tiene una visión amplia del control de convencionalidad, y considera que incluso la Constitución Nacional puede ser invalidada si es contraria a la jurisprudencia de la Corte Interamericana. Ibid., pp. 17 y 19.
} 
definir, además, si las sentencias de la Corte Interamericana tienen un carácter vinculante más allá de los casos que deciden. Esta cuestión de si los órganos nacionales deberían considerar la jurisprudencia interamericana como parte de la CADH también dependería de si sus sistemas jurídicos internos usan el sistema de precedentes, en particular los precedentes internacionales. Por ejemplo, la Corte Suprema de Costa Rica consideró que, dado que la Corte Interamericana es el intérprete "natural" de la CADH, sus interpretaciones tendrían "de principio" el mismo valor que la norma interpretada. ${ }^{106}$ Esta posición es totalmente compatible con la facultad del Estado para definir la relación entre el derecho nacional y el internacional.

\subsection{Complejidades de los enfoques acotados}

El argumento más significativo -aunque hipotético- que puede dirigirse exclusivamente en contra de los enfoques acotados, consiste en afirmar que el enfoque extensivo tiene más potencial para extender el alcance de las decisiones de la Corte Interamericana. Sin embargo, este argumento es cuestionable, ya que la efectividad del control de convencionalidad en su enfoque extensivo, aún depende de la receptividad de los Estados parte. Por ejemplo, en el caso de Chile, la recepción de la doctrina del control de convencionalidad había sido casi inexistente ${ }^{107}$ (aunque recientemente la Corte Suprema apoyaría una versión acotada de tal doctrina ${ }^{108}$ ). Esta actitud no puede asociarse con un desprecio de la Corte, porque Chile ha sido incluido entre los "cinco principales cumplidores" de sus sentencias. ${ }^{109}$

106 Corte Suprema de Costa Rica, 9 de mayo de 1995, Exp. 0421-S-90, Sentencia N 2313-95, considerando VII. También sería el caso de Bolivia, según su Tribunal Constitucional. Tribunal Constitucional Plurinacional de Bolivia, 28 de noviembre de 2017, 0084/2017, Sentencia, p. 19.

${ }^{107}$ HenRíqueZ; NúÑEZ, cit. (n. 100), pp. 401-402.

${ }^{108}$ En efecto, en el reciente antecedente administrativo relativo al caso Norín Catrimán, la Corte Suprema afirmó que las autoridades e integrantes del Estado tienen la obligación de "interpretar sistemática e integralmente las disposiciones que informan el sistema jurídico, de forma tal que sus determinaciones guarden la mayor correspondencia y compatibilidad con las obligaciones internacionales adquiridas soberanamente" por el Estado. Corte Suprema de Chile, 16 de mayo de 2019, Rol N AD-1386-2014, considerando $9^{\circ}$. Esta interpretación corresponde a una interpretación acotada, atendido que la Corte Suprema pide efectuar un control de convencionalidad débil (interpretar la legislación de modo conforme con la $\mathrm{CADH}$-no dice nada sobre la interpretación que de ella haga la Corte Interamericana-), sin exigir que se deje sin efecto la normativa nacional contraria a dicha convención (en efecto, ella dice que las consecuencias de efectuar este control de convencionalidad depende "de las funciones que cada operador de justicia tiene"). Ibid.

${ }^{109}$ Hawkins, Darren; JACOBI, Wade, "Partial Compliance: A Comparison of the European and InterAmerican Courts for Human Rights", Journal of International Law and International Relations, 2010, 
Por lo tanto, parece que otros factores internos influirían más en la recepción de las interpretaciones de la Corte, que la creación de la doctrina del control de convencionalidad.

Otro argumento en contra de los enfoques acotados es que pueden contrariar los fallos de la Corte, pues ésta afirma que los órganos estatales tienen el deber de realizar el control de convencionalidad (en el marco de sus respectivas competencias y de las regulaciones procesales correspondientes), mientras que, según los enfoques acotados, los Estados tienen una mayor o menor libertad para determinar hasta qué punto aplicarán el control de convencionalidad -incluso pueden llegar a decidir no tener ningún control de convencionalidad-. Por lo tanto, según los enfoques acotados, los Estados no tienen el deber de realizar el control. Sin embargo, frente a esta objeción se puede alegar que eso mismo es lo que buscó la Corte Interamericana al establecer la fórmula de "en el marco de sus respectivas competencias y de las regulaciones procesales correspondientes".

Algunas complejidades del enfoque acotado son padecidas sólo por la primera variante (aquella que concede automáticamente el poder para realizar el control de convencionalidad fuerte a todos los órganos que pueden ejercer el control de constitucionalidad). La primera dificultad se refiere a que esta variante supone una equivalencia entre el control de convencionalidad y el control de constitucionalidad, a pesar de que ambas figuras tienen muchas diferencias entre sí, ${ }^{110}$ y que la Corte Interamericana nunca ha establecido una conexión entre la competencia para ejercer el control de constitucionalidad y el control de convencionalidad ${ }^{111}$ (sin perjuicio de que algunos jueces hayan apoyado la idea de que la CADH sería una "Constitución supranacional", ${ }^{112}$ y de que algún autor considera que la Corte ha hecho esta conexión en forma implícita $\left.{ }^{113}\right)$. Atendida esta falta de equivalencia entre los controles

\footnotetext{
Vol. 6, $\mathrm{N}^{\circ} 1$, p. 62.

${ }^{110}$ Castilla, cit. (n. 6), pp. 68-75.

111 Corte IDH, 26 de noviembre de 2010, Cabrera García y Montiel Flores v. México, Excepciones Preliminares, Fondo, Reparaciones y Costas, Sentencia (ser. C) $N^{\circ} 220$, voto concurrente del juez Ferrer Mac-Gregor, párr. 26.

${ }^{112}$ Los entonces jueces ad hoc -y posteriores jueces permanentes de la Corte- Ferrer Mac-Gregor y Caldas, apoyan esta noción. Corte IDH, 26 de noviembre de 2010, Cabrera García y Montiel Flores v. México, Excepciones Preliminares, Fondo, Reparaciones y Costas, Sentencia (ser. C) $N^{\circ} 220$, voto concurrente del juez Ferrer Mac-Gregor párr. 76 (la traducción es del autor).

113 SAGÜÉs, cit. (n. 52), pp. 121-122. Es interesante notar que Sagüés considera que si los jueces no tienen la facultad de remitir casos sobre normas contrarias a la CADH a un juez que pueda ejercer un control de convencionalidad fuerte, deben encontrar formas creativas para que se realice este control.
} 
de constitucionalidad y de convencionalidad, es inadecuado concluir que los jueces que pueden realizar el control de constitucionalidad tienen automáticamente la facultad de realizar el control de convencionalidad fuerte. Sólo en caso de cumplirse algunos requisitos sería posible hacer una analogía entre el control de constitucionalidad y el control de convencionalidad. El más importante de estos requisitos sería que la Constitución nacional otorgue a los tratados internacionales o, al menos, a la $\mathrm{CADH}$, el mismo estatus que el de la Constitución, lo que no siempre ocurre. ${ }^{114}$ Incluso dentro de los Estados que otorgan jurisdicción a la Corte Interamericana, la relación entre su Derecho interno y el Derecho internacional puede ser muy diferente. ${ }^{115}$

Una segunda complejidad de esta variante, es que la Corte Interamericana no afirma que los órganos del Estado deban realizar el control de convencionalidad debido a la incorporación constitucional de la $\mathrm{CADH}$, sino por el mero hecho de que sus Estados son parte de la CADH. ${ }^{116}$ En efecto, la Corte considera que la condición de Estado parte de la CADH crea el deber de aplicar directamente las interpretaciones de la Corte sobre este tratado, ${ }^{117}$ tomando la posición de que la CADH debiera ser inherentemente autoejecutable. ${ }^{118}$ Frente a esta complejidad, habría que recalcar que la Corte Interamericana no está facultada para decidir sobre la competencia de los tribunales nacionales, por lo que no puede establecer una conexión obligatoria entre los controles de constitucionalidad y de convencionalidad.

\section{LA POSIBILIDAD DE QUE LA CORTE ADOPTE UN CONTROL DE CONVENCIONALIDAD MÁS ADECUADO}

Según hemos visto, el enfoque extensivo de la doctrina del control de convencionalidad tiene varios problemas que lo hacen incompatible

\footnotetext{
Ibid., p. 122. Por lo tanto, Sagüés parece considerar que los jueces no facultados para ejercer un control de convencionalidad fuerte, aún pueden encontrar formas creativas de garantizar que exista un control de convencionalidad, incluso ejerciéndolo ellos mismos.

114 Por ejemplo, Argentina y Nicaragua.

${ }^{115}$ Véase Instituto Interamericano de Derechos Humanos, cit. (n. 36), pp. 113-121. Algunos Estados otorgan al Derecho internacional una jerarquía constitucional -algunos incluso mencionan la CADH en sus constituciones- mientras que otros guardan silencio sobre esta materia. V. Ibid.

116 Por ejemplo, Corte IDH, 26 de noviembre de 2010, Cabrera García y Montiel Flores v. México, Excepciones Preliminares, Fondo, Reparaciones y Costas, Sentencia (ser. C) № 220, párr. 225.

117 Por ejemplo, Ibid.

118 Pasqualucci, Jo M., The Practice and Procedure of the Inter-American Court of Human Rights, Cambridge University Press, Nueva York, 2014, $2^{\text {a }}$ ed., p. 301.
} 
con reglas bien conocidas del Derecho internacional, e incluso con el texto de la CADH. ${ }^{119}$ Por el contrario, los enfoques acotados otorgan a los Estados más flexibilidad y poder de decisión en la forma en que aplican esta doctrina. Estos enfoques disponen que el control de convencionalidad sea solo aplicado por los órganos nacionales facultados para ello de acuerdo con su propia legislación nacional, o permitirán que los órganos sin atribución específica apliquen un control de convencionalidad débil, y que el control de convencionalidad fuerte sea ejercido sólo por los órganos nacionales facultados para realizar el control de constitucionalidad. La interpretación acotada sería compatible con el Derecho internacional y nacional si se exige que el control de convencionalidad sea aplicado por órganos que tienen la facultad de ejercerlo de acuerdo con su Constitución nacional. Esta competencia puede ser otorgada explícita o tácitamente. Sería concedida en forma tácita cuando la Constitución integre la $\mathrm{CADH}$ entre sus disposiciones (en cuyo caso, el control de constitucionalidad incluiría el análisis de la compatibilidad de las leyes nacionales con los tratados que forman parte de la Constitución). ${ }^{120} \mathrm{Al}$ decir esto, discordamos con la posición que sostiene que los jueces facultados para ejercer el control de constitucionalidad tienen algún tipo de atribución automática para realizar el control de convencionalidad.

Estamos en un momento histórico en que el contenido de la doctrina del control de convencionalidad está en desarrollo, por lo que no es del todo claro. Por eso, la Corte Interamericana aún puede inclinarse por adoptar la posición acotada. Convendría que, en particular, se incline por la posición que requiere una conexión clara (un puente) entre la jurisprudencia de la Corte Interamericana y los sistemas legales nacionales. Si la Corte toma esta posición como propia, estaría adoptando un enfoque compatible con las reglas generales del Derecho internacional y con el Estado de Derecho nacional. Algunos jueces de la Corte Interamericana han demostrado una posición acotada, lo que le brinda a la Corte la posibilidad de definir la doctrina del control de convencionalidad de una manera más delimitada y apropiada. Por el contrario, apoyar la doctrina del control de convencionalidad en su enfoque extensivo no es sostenible, debido a su falta de fundamento jurídico

\footnotetext{
119 Por ejemplo, con el artículo 2 de la CADH, que obliga a los Estados a dar efecto a los derechos y libertades establecidos en ella, "con arreglo a sus procedimientos constitucionales y a las disposiciones de esta Convención".

${ }^{120}$ Como es el caso de Argentina.
} 
en la $\mathrm{CADH}$, y al hecho de que puede ser contraria a las constituciones de ciertos Estados (las que, a menos que el Estado ratifique un tratado en sentido contrario, son soberanas para determinar la relación entre el Derecho interno y el Derecho internacional). En este sentido, da la impresión de que la literatura académica que es crítica de la aplicación del enfoque extensivo va en aumento, por lo que la adopción de un enfoque extensivo por parte de la Corte Interamericana puede tener el paradójico efecto de disuadir a los Estados de adoptar la doctrina del control de convencionalidad.

\section{CONCLUSIONES}

Sergio García Ramírez, expresidente de la Corte Interamericana e iniciador de la doctrina del control de convencionalidad, argumentó que si la Corte y los Estados Partes no están de acuerdo en su comprensión del control de convencionalidad, "el riesgo es que se alimente la dispersión, surjan contradicciones en el interior de los países -no sólo de los países entre sí- y decaiga la tutela continental de los derechos humanos". ${ }^{121}$ Sin detenernos en la exactitud de esta afirmación, ella muestra que hay mucho involucrado en que el control de convencionalidad sea comprendido correctamente.

Existen, al menos, dos lecturas de esta doctrina. La primera, el enfoque extensivo, considera que todos los órganos nacionales deben ejercer siempre el control de convencionalidad -incluso si ello implica invalidar normas internas que contraríen las interpretaciones de la Corte Interamericana-, independientemente de si estos órganos tienen la facultad legal de ejercer el control de constitucionalidad. La segunda lectura, el enfoque acotado, considera que los órganos nacionales solo pueden realizar el control de convencionalidad si tienen la facultad para llevarlo a cabo. Dentro de esta interpretación, algunos autores consideran que todos los órganos nacionales deben ejercer, al menos, un control de convencionalidad débil, y que solo los órganos con competencia para ejercer el control de constitucionalidad deben realizar un control de convencionalidad fuerte. Sin embargo, esta lectura engendra nuevas dificultades, como no explicar por qué los órganos que ejercen el control de constitucionalidad estarían automáticamente facultados para realizar un control de convencionalidad fuerte, considerando que existen muchas diferencias entre ambos controles. Una segunda lectura dentro del

${ }^{121}$ GarcíA, cit. (n. 8), p. 23. 
enfoque acotado requiere una conexión más específica entre el Derecho internacional y los sistemas jurídicos nacionales, como la incorporación de la CADH en las constituciones de los Estados Partes, para justificar la aplicación de la doctrina del control de convencionalidad.

En caso de que la Corte adopte el enfoque extensivo para la aplicación del control de convencionalidad, los Estados podrían tener dificultades para aceptar esta doctrina, debido a su falta de base normativa y efectos demasiado amplios. Por el contrario, si la Corte adopta claramente el enfoque acotado, que es coherente con el poder de los Estados para definir la posición jerárquica y el modo de incorporación de la $\mathrm{CADH}$ a sus ordenamientos jurídicos $-\mathrm{y}$ seguir sus propias tradiciones legales en materia de precedentes-, eliminaría cualquier obstáculo a la aplicación de la doctrina del control de convencionalidad. Además, esta posición sería más compatible con la autonomía de los Estados para determinar el alcance y la aplicación del Derecho internacional en sus regímenes jurídicos internos.

\section{BIBLIOGRAFÍA}

Aguilar Cavallo, Gonzalo, "El Control de Convencionalidad: Análisis en Derecho Comparado", Revista Direito GV, 2013, Vol. 9 (18), № 2.

Antorne, Rose-Marie Belle, Commonwealth Caribbean Law and Legal Systems, Routledge-Cavendish, New York, 2008, $2^{\mathrm{a}}$ ed.

Binder, Christina, "The Prohibition of Amnesties by the Inter-American Court of Human Rights", German Law Journal, 2011, Vol. 12, № 5.

Brewer Carías, Allan, "El Control de Convencionalidad, con Particular Referencia a la Garantía del Derecho a la Protección Judicial Mediante un Recurso Sencillo, Rápido y Efectivo de Amparo de los Derechos Humanos", 2012, disponible en línea: http://allanbrewercarias.com/wp-content/uploads/2012/09/1107-1-1055EL-CONTROL-DE-CONVENCIONALIDAD-por-la-Corte-IDH-Y-AMPARO18-sept.-2012.doc.pdf, fecha de consulta: 16 de noviembre de 2018.

Burgorgue-Larsen, Laurence, "Chronicle of a Fashionable Theory in Latin America. Decoding the Doctrinal Discourse on Conventionality Control", en: Haeck, Y.; Ruiz-Chiriboga, O.; Burbano, C. (eds.), The Inter-American Court of Human Rights: Theory and Practice, Present and Future, Intersentia, Cambridge, 2015

Candia-Falcón, Gonzalo, "El Estado de Derecho y la Corte Interamericana de Derechos Humanos", Díkaion, 2015, Vol. 24, ํ 2.

Carozza, Paolo G.; González, Pablo, "The Final Word? Constitutional Dialogue and the Inter-American Court of Human Rights: A Reply to Jorge 
Contesse", International Journal of Constitutional Law, 2017, Vol. 15, № 2.

CAstilla Jú́Rez, Karlos A., ¿Control Interno o Difuso de Convencionalidad? Una Mejor Idea: La Garantía de Tratados", Anuario Mexicano de Derecho International, 2013, $\mathrm{N}^{\circ}$ XIII.

Cheng, Bin, General Principles of Law as Applied by International Courts and Tribunals, Cambridge University Press, Cambridge, 2006, reimpresión.

Contreras VÁsquez, Pablo, "Análisis Crítico del Control de Convencionalidad”, en: Núñez, M. (ed.), La Internacionalización del Derecho Público, Thomson Reuters - La Ley, Santiago, 2015.

DulitzKy, Ariel E., “An Inter-American Constitutional Court? The Invention of the Conventionality Control by the Inter-American Court of Human Rights", Texas International Law Journal, 2015, $\mathrm{N}^{\circ} 50$.

Ferrer Mac-Gregor, Eduardo, "Conventionality Control: The New Doctrine of the Inter-American Court of Human Rights" (2015) AJIL Unbound, 2015, N 109.

Ferrer Mac-Gregor, Eduardo, "El Control de Convencionalidad en la Jurisprudencia de la Corte Interamericana de Derechos Humanos (A Una Década de su Creación: 2006-2016)", en: Henríquez, M.; Morales, M. (eds.), El Control de Convencionalidad: Un Balance Comparado a 10 Años de Almonacid Arellano vs. Chile, Ediciones Der, Santiago, 2017.

Fuentes Torrijo, Ximena, "International and Domestic Law: Definitely an Odd Couple", Revista Jurídica de la Universidad de Puerto Rico, 2008, № 77.

García Ramírez, Sergio, "Control de Convencionalidad” en: Henríquez, M.; Morales, M. (eds.), El Control de Convencionalidad: Un Balance Comparado a 10 Años de Almonacid Arellano vs. Chile, Ediciones Der, Santiago, 2017.

GARner, Bryan A. (ed.), Black's Law Dictionary, Thomson Reuters, Minnesota, 2014, 10 a ed.

GonzÁlez Domínguez, Pablo, "La Doctrina del Control de Convencionalidad a la Luz del Principio de Subsidiariedad", Estudios Constitucionales, 2017, Vol. $15, \mathrm{~N}^{\circ} 1$.

Hawkins, Darren; JACOBI, Wade, "Partial Compliance: A Comparison of the European and Inter-American Courts for Human Rights", Journal of International Law and International Relations, 2010, Vol. 6, $\mathrm{N}^{\circ} 1$.

Henríquez ViÑAs, Miriam Lorena, "La Polisemia del Control de Convencionalidad Interno", International Law. Revista Colombiana de Derecho Internacional, 2014, Vol. 24.

Henríquez Viñas, Miriam Lorena; Núñez Leiva, José Ignacio, “Control de Convencionalidad en Chile. Un Soliloquio en 'El Laberinto de la Soledad"' en: Henríquez, M.; Morales, M. (eds.), El Control de Convencionalidad: Un Balance Comparado a 10 Años de Almonacid Arellano vs. Chile, Ediciones Der, Santiago, 2017.

Huneeus, Alexandra, "Constitutional Lawyers and the Inter-American 
Court's Varied Authority", Law and Contemporary Problems, 2016, Vol. 79, № 1 . Instituto Interamericano de Derechos Humanos, Manual Auto-Formativo para la Aplicación del Control de Convencionalidad Dirigido a Operadores de Justicia, Instituto Interamericano de Derechos Humanos, San José de Costa Rica, 2015.

Julio Estrada, Alexei, “ComentarioalArtículo 'Control de Convencionalidad Interamericano: Una Mera Aplicación del Derecho Internacional', de Karlos A. Castilla Juarez", Revista Derecho del Estado (U. Externado de Colombia), 2015, $\mathrm{N}^{\circ} 34$.

Maino, Carlos Alberto Gabriel, "El Control de Convencionalidad y las Dificultades que Ofrecen las Interpretaciones de la CIDH”, Prudentia Iuris, 2016, $N^{\circ} 81$.

Malarino, Ezequiel, "Acerca de la Pretendida Obligatoriedad de la Jurisprudencia de los Órganos Interamericanos de Protección de Derechos Humanos para los Tribunales Judiciales Nacionales", en: Steiner, C. (ed.), Sistema Interamericano de Protección de los Derechos Humanos y Derecho Penal Internacional, Konrad-Adenauer-Stiftung e. V., Montevideo, 2011,

Nogueira Alcalá, Humberto, "Los Desafíos del Control de Convencionalidad del Corpus Iuris Interamericano para las Jurisdicciones Nacionales", Boletín Mexicano de Derecho Comparado, 2012, Año XLV, Vol. 135.

NogueIra Alcalá, Humberto, "Sistema Interamericano de Protección de Derechos Humanos, Control de Convencionalidad y Aplicación por Parte de las Jurisdicciones Nacionales", en: Nogueira, H. (ed.), La Protección de los Derechos Humanos y Fundamentales de Acuerdo a la Constitución y el Derecho Internacional de los Derechos Humanos, Centro de Estudios Constitucionales de Chile - Librotecnia, Santiago, 2014.

PAúl, Álvaro, "Cuatro Extendidos Desaciertos de la Corte Interamericana que se Observan en su Opinión Consultiva $\mathrm{N}^{\circ}$ 24" en: Facultad de Derecho de la Universidad Diego Portales; Figueroa, R. (eds.), Anuario de Derecho Público 2018, Ediciones Universidad Diego Portales, Santiago, 2018.

Paúl, Álvaro, Los Trabajos Preparatorios de la Declaración Americana de los Derechos y Deberes del Hombre y el Origen Remoto de la Corte Interamericana, Universidad Nacional Autónoma de México, Instituto de Investigaciones Jurídicas, México, 2017.

Pisillo Mazzeschi, Riccardo, "Responsabilité de l'État pour Violation des Obligations Positives Relatives aux Droits de 1'Homme", Recueil des Cours (Académie de Droit International), 2008, N 333.

SAGÜÉs, Nestor Pedro, "El 'Control de Convencionalidad' en el Sistema Interamericano y sus Anticipos en el Ámbito de los Derechos Económico-Sociales. Concordancias y Diferencias con el Sistema Europeo", en: Ferrer Mac Gregor, E.; Herrera García, A. (coords.), Diálogo jurisprudencial en derechos humanos 
entre tribunales constitucionales y cortes internacionales: in memoriam Jorge Carpizo, generador incansable de diálogos, Tirant Lo Blanch, Valencia, 2013, pp. 993-1030, disponible en línea, http://www.corteidh.or.cr/tablas/r27778.pdf, 16 de noviembre de 2018.

SAGÜÉs, Nestor Pedro, "Derecho Internacional y Derecho Constitucional. Dificultades Operativas del Control de Convencionalidad en el Sistema Interamericano", en: Ahrens, H. (ed.), El Estado de Derecho Hoy en América Latina. Libro en Homenaje a Horst Schönbohm, GIZ - Konrad Adenauer Stiftung, Berlín - México, D.F., 2012.

SAGÜÉs, Nestor Pedro, "Obligaciones Internacionales y Control de Convencionalidad", en: Instituto de Justicia Constitucional Corte de Constitucionalidad \& Asociación Cívica Instituto de Gobernanza (eds.), Opus Magna Constitucional Guatemalteca, Instituto de Justicia Constitucional, Guatemala, 2011.

SAGÜÉs, Nestor Pedro, "Obligaciones Internacionales y Control del Convencionalidad”, Estudios Constitucionales, 2010, Vol. 8, N 1.

Secretaría General de la Organización de los Estados Americanos, Conferencia Especializada Interamericana sobre Derechos Humanos: Actas y Documentos, OEA/Ser.K/XVI/1.2, San José, Costa Rica, 7-22 de Noviembre de 1969, Secretaría de la Comisión Interamericana de Derechos Humanos, Washington, D.C., 1973.

Shaw, Malcolm N., International Law, Cambridge University Press, Cambridge - New York, 8 a ed., 2017.

Silva Aввот, Max, "Control de Convencionalidad Interno y Jueces Locales: Un Planteamiento Defectuoso", Estudios Constitucionales, 2016, Vol. 14, № 2. 